\title{
Benefit risk assessment and update on the use of docetaxel in the management of breast cancer
}

\author{
This article was published in the following Dove Press journal: \\ Cancer Management and Research \\ II October 2013 \\ Number of times this article has been viewed
}

\author{
Scheryll Alken \\ Catherine M Kelly \\ Department of Medical Oncology, \\ Mater Misericordiae University \\ Hospital, Dublin, Ireland
}

Correspondence: Catherine M Kelly Department of Medical Oncology, Mater Misericordiae University Hospital, University College Dublin, Eccles Street,

Dublin 7, Ireland

Tel +3538032990

Fax +3538032404

Email catherine.kelly@ucd.ie

\begin{abstract}
The objective of this paper is to review the data supporting the use of docetaxel in the treatment of breast cancer, focusing on pharmacokinetics, efficacy in adjuvant and metastatic trials alone and in combination with chemotherapeutic and targeted agents, and the toxicity of docetaxel in comparison to paclitaxel. Docetaxel is a semisynthetic product derived from the European yew tree Taxus baccata L. It promotes the assembly of microtubules, stabilizes them, and thereby prevents their depolymerization. Docetaxel has been incorporated into neo-adjuvant chemotherapy regimens, both with and without anthracyclines. The inclusion of taxanes such as docetaxel in polychemotherapy regimens in early breast cancer is associated with a statistically significant reduction in mortality. As a single agent, docetaxel is highly active in the treatment of metastatic breast cancer. In first-line treatment of metastatic breast cancer, the combination of docetaxel and capecitabine was associated with an improvement in overall survival; however, toxicity was higher. The toxicity profile of docetaxel has been well documented and is predictable; the most frequent adverse effects are neutropenia and febrile neutropenia. Taxane-specific adverse effects, such as peripheral neuropathy, are also expected but are manageable with appropriate dosing and scheduling.
\end{abstract}

Keywords: taxanes, docetaxel, clinical trial, adverse effects, peripheral neuropathy, neutropenia

\section{Introduction: management issues in the treatment of breast cancer}

Breast cancer is the most frequently diagnosed cancer in women and is the leading cause of mortality among women after lung cancer. ${ }^{1}$ Considerable improvements in breast cancer survival have occurred through the widespread adoption of breast cancer screening and through multidisciplinary care. ${ }^{2}$ For many years, physicians treating breast cancer have recognized it to be a diverse and heterogeneous group of diseases, each manifesting a different clinical course and response to therapy. Seminal research by Perou and colleagues ${ }^{3}$ over a decade ago described the intrinsic breast cancer subtypes, each with a distinct transcriptional profile: luminal A, luminal B, basal-like, human epidermal growth factor receptor 2 (HER2)-enriched, and normal-like. ${ }^{3}$

Because gene expression profiling is not routinely performed in the clinical setting, immunohistochemical surrogates using the estrogen receptor (ER), progesterone receptor (PR), and HER2 are used to classify breast cancers into subtypes, although this classification is not optimal. In the broadest sense, luminal A and B are ER-positive, but the latter subtype has a higher proliferation rate and is more responsive to chemotherapy, and is less responsive to endocrine therapy. ${ }^{4}$ The HER2-enriched subtype comprises HER2-positive breast cancers that can be ER-positive or ER-negative. 
Finally, the triple-negative breast cancer (TNBC) subgroup comprises ER-negative, PR-negative, and HER2-negative cancers. Most basal-like breast cancers fall into the TNBC group; however, not all TNBCs are basal-like. ${ }^{5}$ The TNBC subgroup is also subdivided further based on gene expression profiling; this more in-depth classification may lead to better treatment selection. ${ }^{6}$

\section{Management issues for patients with early stage breast cancer}

Women diagnosed with early-stage breast cancer, that is, with no evidence of metastatic disease, are considered for adjuvant chemotherapy, with the objective of treating occult micrometastatic disease. The observation that chemotherapy is most effective when the tumor volume is small and cancer cells are in the linear growth phase led to the initial randomized controlled trials of polychemotherapy versus observation in patients with lymph node-positive breast cancer. ${ }^{7}$ These early clinical trials showed improvements in disease-free survival (DFS) and overall survival (OS) in favor of chemotherapy compared to observation alone. ${ }^{8}$

Subsequently, in 1988, based on the early results of several randomized trials that evaluated systemic therapy in lymph node-negative breast cancer, the US National Cancer Institute (NCI) issued a "clinical alert." The recommendation issued by the 2000 National Institutes of Health (NIH) Consensus Conference was that chemotherapy should be considered in all women with tumors larger than $1 \mathrm{~cm}$ and in women with positive lymph nodes. The Early Breast Cancer Trialists' Collaborative Group (EBCTCG), established in 1984, conducts 5-yearly worldwide meta-analyses of centrally collected data from every patient enrolled in all randomized trials that have been running for at least 5 years. These meta-analyses have also provided extensive evidence showing the efficacy of adjuvant chemotherapy in early breast cancer and provide an important reference point for medical oncologists. ${ }^{9}$

The EBCTCG meta-analyses of randomized trials showed that anthracycline-containing regimens were superior to first-generation non-anthracycline-containing multi-agent regimens such as the combination of cyclophosphamide, methotrexate, and fluorouracil (CMF). Anthracycline-based regimens given for approximately 6 months were shown to reduce annual breast cancer death rates by approximately $38 \%$ for women younger than 50 years at diagnosis and by $\sim 20 \%$ for women between 50 and 69 years of age at diagnosis. ${ }^{10}$ The most recent EBCTCG overview analysis, published in 2012, includes treatment results from more than 20,000 women randomized to a taxane compared with a nontaxane-containing regimen, and found an improvement in recurrence-free survival (RFS) (hazard ratio [HR], $0.83 ; P<0.00001$ ) with the addition of a taxane to adjuvant chemotherapy. ${ }^{9}$

There are many adjuvant regimens considered "standard," and most were evaluated in clinical trials before the last decade, at a time when breast cancer was considered a single disease entity. There have been considerable improvements in the way that patients are selected: those women with hormone-receptor positive, lymph-node negative breast cancers can safely avoid chemotherapy and a number of commercially available gene expression-based tools can assist in the decision. ${ }^{11,12}$ For patients who do require chemotherapy, selecting the optimum adjuvant chemotherapy regimen takes into consideration the tumor biology (ER, PR, or HER2 status), and patient factors, such as the presence of comorbidities, for example, congestive heart failure, and peripheral neuropathy. The side effects and toxicities of modern adjuvant chemotherapy are largely transient and reversible; chronic, irreversible side effects (cardiomyopathy, acute myelogenous leukemia, myelodysplastic syndrome) are rare. $^{13}$

\section{Management issues for patients with metastatic disease}

For women presenting with breast cancer recurrence or de novo metastatic disease, a different management approach should be taken. The goal for the vast majority of these patients, unfortunately, is not to find a cure, but rather to prolong their survival while at the same time maintaining their quality of life. In contrast to the adjuvant setting where multi-agent chemotherapy regimens containing anthracyclines and/or taxanes are standard, the single-agent therapy approach is preferred in metastatic disease, unless rapid disease control is required in view of pending visceral crisis.

When treating metastatic disease, consideration of the breast cancer subtype, previous therapies given in the adjuvant setting, time from adjuvant therapy to recurrence, and duration of response to prior endocrine, chemotherapeutic and targeted agent, is required. Patient factors are extremely important, such as the sites and burden of metastatic disease, comorbid illnesses, and previous chemotherapy side effects, eg, peripheral neuropathy, myelosuppression, cardiotoxicity. When there is no clearly optimal chemotherapeutic agent, factors such as the distance from the hospital, estimated 
infusion time for intravenous agents, and other practical considerations must be discussed with the patient on an individual basis. ${ }^{14}$

\section{Overview of the pharmacology of docetaxel}

Taxanes disrupt the equilibrium between polymerized and depolymerized forms of microtubules, the cellular structures required for cell division. As a result, the ability of the mitotic spindle to partition DNA into the two daughter cells formed during cell division is compromised. There are two commercially available taxanes: docetaxel (Taxotere ${ }^{\circledR}$, Sanofi Aventis, Bridgewater, NJ, USA), and paclitaxel (Taxol ${ }^{\circledR}$, Bristol-Meyers Squibb, New York, NY, USA). Paclitaxel is a plant product extracted through fermentation of the trunk bark of Taxus brevifolia. ${ }^{15}$

Docetaxel is a semisynthetic product of the European yew tree Taxus baccata L. ${ }^{16}$ It promotes the assembly of microtubules, stabilizes them, and thereby prevents depolymerization. This leads to blocking of the $\mathrm{M}$ phase of the cell cycle and thereby interferes with the ability of cells to divide. ${ }^{17}$ Docetaxel was synthesized from the 10 -deacetyl baccatin IIIa noncytotoxic precursor extracted from the needles of Taxus baccata and esterified with a chemically synthesized side chain (Figure 1). The binding affinity of docetaxel for the beta-tubulin sub-unit is 1.9 , versus 1.0 for that of paclitaxel. ${ }^{18-20}$ Docetaxel binds to the tau binding site; in contrast, paclitaxel binds to the N-terminal of 31 amino acids of beta-tubulin..$^{20}$ Docetaxel has twice the potency of paclitaxel: in contrast to paclitaxel, it affects the centrosome, which interacts with the mitotic spindle. However, docetaxel is susceptible to cellular drug resistance caused by drug efflux via a number of multidrug resistanceassociated proteins.

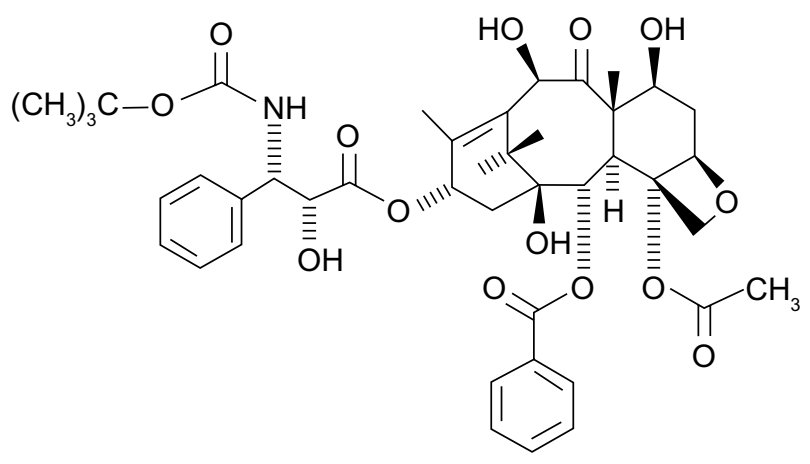

Figure I Chemical structure of docetaxel.

\section{Docetaxel pharmacokinetics}

Docetaxel has a three-compartment pharmacokinetic profile. It's pharmacokinetics are linear. It is metabolized by the cytochrome P450-3A subfamily isoenzymes. Peak levels of docetaxel vary according to the dosing and schedule of administration, with higher peak levels associated with shorter infusions. After 7 days, most (75\%) of the drug was eliminated in the feces, with a lesser amount in urine $(5 \%)$ following intravenous administration; however, most of the drug was eliminated within the first 2 days. When docetaxel is given with cisplatin, clearance of both agents remains unaffected by the other. ${ }^{21}$

\section{Clinical trials examining the activity of docetaxel in metastatic and early breast cancer Phase II clinical trials of docetaxel in breast cancer}

Promising results in the preclinical and Phase I setting led to the examination of docetaxel in Phase II studies. The initial Phase II trial examined the activity of docetaxel as first-line therapy for women with metastatic breast cancer and showed an objective response rate (ORR) of $67.7 \%$ (95\% confidence interval [CI] 49\%-83\%). Similar results were found in the Phase II collaborative European Organization for Research and Treatment of Cancer (EORTC) trial where the ORR was $51 \%$ (95\% CI 34\%-69\%) in heavily pretreated women who had received up to three prior lines of chemotherapy for metastatic breast cancer. ${ }^{22}$ The dosage and scheduling was identical in these studies, with docetaxel administered at $100 \mathrm{mg} / \mathrm{m}^{2}$ every 3 weeks. The dose-limiting toxicity was neutropenia.

\section{Docetaxel in the treatment of metastatic} breast cancer

These impressive objective response rates in Phase II trials led to further evaluation of docetaxel in Phase III randomized controlled trials. In a direct head-to-head comparison with doxorubicin in patients with advanced disease who had previously been treated with an alkylating agent, docetaxel showed a statistically significant $(P=0.008)$ improvement in the overall response rate: $47.8 \%$ versus $33.3 \%{ }^{23}$ Once more, the efficacy of docetaxel in patients traditionally considered "poor risk", ie, those with visceral metastases and chemoresistance, was shown. Unlike an anthracycline, docetaxel is not limited by a maximum dose, allowing patients to continue treatment with the drug until progression or toxicity occurs. 
The majority of patients in 2013 will have received anthracyclines in the adjuvant setting. In a randomized Phase III trial, docetaxel was compared to a mitomycin and vinblastine in anthracycline pre-treated patients. ${ }^{24}$ This study demonstrated an improvement in the ORR of $18.4 \%(11.6 \%$ compared with $30 \%, P<0.0001)$. This translated into an improvement in time to progression (11 months versus 19 months, $P=0.001)$, and OS (11.4 versus $8.7, P=0.0097)$. This survival benefit persisted when statistics were adjusted for post-study treatment.

As docetaxel was found to be a highly active single-agent treatment in metastatic breast cancer, further studies considered whether that activity could be increased by combining it with other agents. There are three randomized controlled trials that evaluated the role of docetaxel in combination with another agent versus docetaxel alone. ${ }^{25-27}$ Each of these studies assessed the docetaxel doublet in the setting of patients previously exposed to anthracycline treatment.

O'Shaughnessy et $\mathrm{al}^{25}$ assessed the efficacy of docetaxel in combination with capecitabine, an oral 5-FU prodrug with preferential uptake into tumor cells. They demonstrated an improved time to progression from 4.2 months in the single-agent arm to 6.1 months in the combination arm (HR 0.652; $P=0.0001)$. They also demonstrated an improved OS from 11.5 months (95\% CI 9.8-12.7) to 14.5 months (95\% CI 12.3-16.3) in the combination arm. Interestingly, the tolerability and patient quality of life measures showed no deterioration in the combination arm.

Pacilio et $\mathrm{al}^{26}$ investigated the combination of docetaxel with epirubicin, an anthracycline associated with good response in breast cancer and also having decreased cardiac toxicity relative to doxorubicin. Again, all these women were anthracycline-pretreated but had received no prior cytotoxic treatment for metastatic disease. The study closed prematurely due to poor recruitment, which the authors attributed to strict inclusion criteria; therefore, the data must be interpreted with that in mind. They demonstrated a reduced objective response rate ( $72 \%$ versus $79 \%$ ) in the combination arm along with shorter OS (18 months versus 21 months).

Sparano et $\mathrm{al}^{27}$ investigated an anthracycline in combination with docetaxel. However, in this study, the researchers used pegylated liposomal doxorubicin, which is associated with a decreased incidence of cardiac toxicity and has been demonstrated to be safe in patients at their maximal cumulative lifetime doxorubicin dose. The results demonstrated an improved time to progression in the combination arm (9.8 versus 7.0 months), along with an improved objective response rate $(35 \%$ versus $26 \% ; P=0.085)$. Interestingly, this did not translate into an improved OS, a factor the authors attributed to the extensive post-study treatment in the single agent arm (Table 1).

\section{Docetaxel in the adjuvant treatment of early breast cancer}

Activity in the metastatic setting led to clinical trials designed to determine whether the addition of a taxane (paclitaxel or docetaxel) to anthracycline-containing regimens could improve outcomes in the adjuvant treatment of breast cancer. Recently, a number of meta-analyses have been performed that collate the results of trials over the past number of years. The EBCTCG members published their review in The Lancet in 2012, assessing the effects of polychemotherapy on outcomes in early breast cancer. ${ }^{9}$ They examined individual patient data between 2005-2010 for all trials containing taxanes commenced between 1973 to 2003. They accumulated 100,000 patient results for analysis; approximately 12,000 of these patients were involved in trials based on taxane therapy. The authors found that the 8-year breast cancer mortality was $21.1 \%$ for all patients treated with a taxane compared with $23.9 \%$ for those treated with control regimens. ${ }^{9}$ This represents a statistically significant $(P=0.0005)$ absolute gain of $2.8 \%$. A recent Cochrane review of just under 20,000 patients in clinical trials published online and in print between 1995 and January 2007 showed an improvement in favor of taxane based therapy, with a HR of 0.81 (95\% CI $0.75-0.88$ ), and again, a benefit in risk of recurrence (HR 0.81 ; 95\% CI 0.77-0.86). ${ }^{28}$ These reviews identified seven studies that evaluated docetaxel in adjuvant breast cancer: Breast Cancer International Research Group (BCIRG) 001, ${ }^{29}$ Breast International Group (BIG) 02-98, ${ }^{30}$ E2197, ${ }^{31}$ FinHer, ${ }^{32}$ PACS01, ${ }^{33}$ Taxit216, ${ }^{34}$ and US Oncology $9735 .{ }^{35}$

In the BCIRG 001 study, docetaxel was substituted for fluorouracil in combination with doxorubicin and cyclophosphamide in a 3-weekly cycle. ${ }^{29}$ This study included patients with node-positive disease only and was initiated in the pretrastuzumab era; it demonstrated a $28 \%$ reduction in risk of relapse, with an HR of 0.72 (95\% CI 0.59-0.88). ${ }^{29}$ This translated into a 10 -year DFS of $76 \%$ versus $69 \%$. The benefit of docetaxel was maintained across all treatment groups. ${ }^{29}$

BIG 02-98 was a four-armed study that aimed to answer two questions: was there a benefit from adding docetaxel to standard chemotherapy; and was concurrent or sequential therapy better. ${ }^{30}$ However, analysis was performed at an earlier than planned time because of a lower than expected rate of relapse; less than two-thirds of the events had occurred by the time of analysis (although this change to protocol had been discussed with study investigators). It demonstrated an improvement in DFS in sequential docetaxel (doxorubicin for 
Table I Randomized trials of docetaxel in combination

\begin{tabular}{|c|c|c|c|}
\hline Author & O'Shaughnessy et $a^{25}$ & Pacilio et $\mathrm{al}^{26}$ & Sparano et al ${ }^{27}$ \\
\hline Study design & Randomized & Randomized & Randomized \\
\hline Primary endpoint & TTP & ORR & TTP \\
\hline Secondary endpoint & OS, ORR & OS, TTP & OS, ORR \\
\hline Investigational arm & $\begin{array}{l}\text { Capecitabine } 1,250 \mathrm{mg} / \mathrm{m}^{2} \\
\text { twice daily on days I to } 14 \text { and } \\
\text { docetaxel } 75 \mathrm{mg} / \mathrm{m}^{2} \text { on day I }\end{array}$ & $\begin{array}{l}\text { Epirubicin } 75 \mathrm{mg} / \mathrm{m}^{2} \text { and } \\
\text { docetaxel } 80 \mathrm{mg} / \mathrm{m}^{2}\end{array}$ & $\begin{array}{l}\text { Pegylated liposomal doxorubicin } 30 \mathrm{mg} / \mathrm{m}^{2} \\
\text { and docetaxel } 60 \mathrm{mg} / \mathrm{m}^{2}\end{array}$ \\
\hline Control arm & Docetaxel $100 \mathrm{mg} / \mathrm{m}^{2}$ on day I* & Docetaxel $100 \mathrm{mg} / \mathrm{m}^{2}$ on day I* & Docetaxel $75 \mathrm{mg} / \mathrm{m}^{2}$ on day I* \\
\hline Patient population & $\begin{array}{l}\text { Anthracycline-pretreated } \\
\text { metastatic breast cancer }\end{array}$ & $\begin{array}{l}\text { Anthracycline-pretreated in the } \\
\text { neoadjuvant/adjuvant setting. } \\
\text { No previous chemotherapy } \\
\text { for metastatic breast cancer }\end{array}$ & $\begin{array}{l}\text { Anthracycline-pretreated in the neoadjuvant/ } \\
\text { adjuvant setting; prior hormonal treatment } \\
\text { and/or one regimen of chemotherapy for } \\
\text { metastatic disease were acceptable }\end{array}$ \\
\hline
\end{tabular}

Note: *All regimens are 3-week cycles.

Abbreviations: TTP, time to progression; ORR, objective response rate; OS, overall survival.

three cycles, docetaxel for three cycles, cyclophosphamide, methotrexate, fluorouracil (CMF) for four cycles) compared with standard chemotherapy (doxorubicin for four cycles, CMF for three cycles). The triple-agent group had an HR of $0.79(95 \%$ CI $0.65-0.98, P=0.035) .{ }^{30}$ There was also a benefit in sequential rather than concurrent docetaxel, with an HR of 0.83 . This data must obviously be interpreted with caution, given the unplanned timing of the analysis.

E2197 assessed the role of docetaxel in combination with doxorubicin compared with the standard of doxorubicin/ cyclophosphamide..$^{31}$ The majority of patients $(66 \%)$ were node negative, in contrast to those in BCIRG 001. ${ }^{31}$ The authors found no difference in disease-free survival in the E2197 study, although there was an improvement in patients who were ER and PR-negative.

The FinHer study was a four-arm study that not only investigated the role of docetaxel, but also that of trastuzumab. ${ }^{32}$ Patients in this trial were stratified according to HER2/neu status. If negative, they were randomized to receive either docetaxel or vinorelbine. Patients with HER2positive disease were randomized between the chemotherapy arms and also between trastuzumab and non-trastuzumab regimens. These randomizations were then added to standard 5-fluorouracil, epirubicin, and cyclophosphamide (FEC) therapy. Among the 1,010 patients included in this study, all were either node positive or had high-risk disease (tumor size $>2 \mathrm{~cm}$, hormone-receptor negative). There was a clear benefit from docetaxel treatment, with an HR of 0.58 (95\% CI $0.40-0.85, P=0.005$ ) in respect to recurrence or death without recurrence. ${ }^{32}$

The PACS01 study included node-positive patients and randomized them either to six three-weekly cycles of fluorouracil, epirubicin, cyclophosphamide (FEC) 100 or to three cycles of FEC100, followed by docetaxel for three cycles. The study showed an improved 8 -year overall survival of $83.2 \%$ versus $78 \%$, with an HR of $0.75(95 \%$ CI $0.62-0.92, P=0.007) .{ }^{33}$ The authors commented on the benefit seen in two patient populations that are considered high risk: in patients who were HER2/neu positive and in those who had a high Ki67 score. Ki67 is a cellular marker for proliferation.

The Taxit 216 trial randomized lymph node-positive patients to epirubicin for four cycles, followed by CMF for four cycles or sequential docetaxel for four cycles after four cycles of epirubicin and before four cycles of $\mathrm{CMF}^{34}$ There was a $21 \%$ reduction in the risk of relapse in the docetaxel arm; however, this did not achieve statistical significance. ${ }^{34}$

The US Oncology 9735 trial compared docetaxel in combination with cyclophosphamide (TC) to doxorubicin and cyclophosphamide (AC); this was the first of the trials discussed in the present review to do so. ${ }^{35}$ It included both node-negative (48\%) and node-positive patients. There was an improvement in both DFS and OS in the TC arm: DFS of $86 \%$ compared to $80 \%$, with an HR of $0.67(95 \% \mathrm{CI}$ $0.50-0.94, P=0.015)$; the OS HR was $0.76(95 \%$ CI 0.52 $1.1 ; P=0.13) .{ }^{35}$ This study offers a reasonable and efficacious alternative to anthracycline-containing regimens for both node-positive and node-negative breast cancer.

In 2009, the UK TACT trial was published in The Lancet. ${ }^{36}$ This trial assessed the role of sequential docetaxel as adjuvant chemotherapy in early breast cancer. All patients had node-positive disease or their disease had high-risk features (eg, grade 3, hormone receptor negative, lymphovascular invasion present). This study randomized patients to four cycles of FEC, followed by four cycles of docetaxel or a control arm of the physicians' choice: either four cycles of epirubicin followed by four cycles of CMF, or eight cycles of CMF. Interestingly the study failed to show any improvement in OS or DFS with the addition of docetaxel, although there was a trend toward better DFS for HER2/neu positive 
Table 2 Common toxicities in Phase II trials of docetaxel in the metastatic setting

\begin{tabular}{lll}
\hline & Fumoleau et $\mathbf{a l}^{43}$ & Valero et al ${ }^{22}$ \\
\hline Dose administered & $100 \mathrm{mg} / \mathrm{m}^{2}$ & $100 \mathrm{mg} / \mathrm{m}^{2}$ \\
Neutropenia (grade 3-4) & $97 \%$ & $96 \%$ \\
Fluid retention & $89 \%$ & $43 \% *$ \\
Neurosensory disorders & $81.1 \%$ & $6 \%$ \\
\hline
\end{tabular}

Note: *Protocol modification at midpoint analysis commenced prophylactic corticosteroid therapy for edema.

disease. ${ }^{36}$ There was no benefit observed with the addition of a taxane in terms of DFS (HR 0.95; 95\% CI 0.85-1.08; $P=0.44$ ). Suboptimal anthracycline dosing prior to the delivery of docetaxel may have factored into the lack of reported benefit. More recently, Martin et $\mathrm{al}^{37}$ examined the role of docetaxel in high-risk, node-negative breast cancer patients, each having a minimum of ten nodes evaluated for metastatic disease. The substitution of docetaxel for fluorouracil was associated with a $24 \%$ reduction in the risk of death (HR 0.76 ; 95\% CI $0.45-1.26) .{ }^{37}$ The number of patients needed to treat to prevent one death was $17 .{ }^{37}$

These studies demonstrate two points: docetaxel in combination with cyclophosphamide is an effective regimen; and there is benefit in its use in combination in the adjuvant setting. There is a trend toward a particular benefit in patients who are HER2/neu positive.

Neoadjuvant docetaxel given sequentially with $\mathrm{AC}$ was studied in the NSABP B27 trial; no difference in DFS or OS was observed.$^{38}$ This trial was underpowered to detect the observed differences with statistical significance; however, the addition of four cycles of docetaxel to standard AC increased the rate of pathological complete response from $14 \%$ to $26 \%$.

\section{Taxane scheduling}

The ECOG 1199 study provided evidence for the importance of scheduling in taxane treatment. ${ }^{39}$ In this study, almost 5,000 patients with node-positive breast cancer were randomized in a two by two factorial design to four different taxane regimens: four cycles of paclitaxel $175 \mathrm{mg} / \mathrm{m}^{2}$ every 3 weeks;
12 cycles of paclitaxel $80 \mathrm{mg} / \mathrm{m}^{2}$ given weekly; four cycles of docetaxel $100 \mathrm{mg} / \mathrm{m}^{2}$ every 3 weeks; or 12 cycles of docetaxel $35 \mathrm{mg} / \mathrm{m}^{2}$ given weekly after completion of four cycles of AC. The DFS rates were $76.9 \%$ for a 3 -week paclitaxel cycle; $81.5 \%$ for weekly paclitaxel; $81.2 \%$ for a 3 -week docetaxel cycle; and $77.6 \%$ for weekly docetaxel. Improvements in OS were observed for weekly paclitaxel and 3-week docetaxel cycle in comparison with paclitaxel alone given every 3 weeks.

\section{Safety and tolerability profile}

The toxicity profile of docetaxel can be divided into those commonly seen with other chemotherapeutic agents, eg, neutropenia, and those that are specific to the taxane group, eg, peripheral neuropathy. Common toxicities found in Phase II studies included neutropenia, febrile neutropenia, and neurosensory disturbances (Table 2). These toxicities were observed in Phase III data both in the metastatic and adjuvant setting (Table 3). Docetaxel induced fluid retention is a commonly observed adverse effect (AE) that is cumulative in severity and incidence. In some patients, it can be severe, with development of ascites, pleural, or pericardial effusions. The administration of corticosteroid premedication has been shown to reduce the time to onset and severity of fluid retention and is given to all patients. Sodium restriction and judicious use of diuretics is also advised while undergoing treatment with docetaxel. Premedication with corticosteroids is also required to reduce the risk of severe hypersensitivity reactions manifested by hypotension, bronchospasm, and rash/erythema that may occur early into an infusion of docetaxel. Protein-bound paclitaxel particles (Abraxane ${ }^{\circledR}$; Celgene Corporation, Summit, NJ, USA) are an alternative taxane option for patients with metastatic breast cancer where it may be necessary to avoid corticosteroids.

A particularly debilitating side effect of docetaxel given on a weekly schedule is epiphora caused by dacryostenosis. This occurs as a result of chronic inflammation of the epithelial lining as a result of docetaxel-containing tears

Table 3 Common toxicities associated with docetaxel

\begin{tabular}{|c|c|c|c|c|c|}
\hline Trial & Chan et $\mathrm{al}^{23}$ & BCIRG-00I I & BIG 02-98 30 & $E 2917^{31}$ & BCIRG-006 ${ }^{44}$ \\
\hline Dose administered & $100 \mathrm{mg} / \mathrm{m}^{2}$ & $75 \mathrm{mg} / \mathrm{m}^{2}$ & $50-100 \mathrm{mg} / \mathrm{m}^{2}$ & $60 \mathrm{mg} / \mathrm{m}^{2}$ & $75-100 \mathrm{mg} / \mathrm{m}^{2}$ \\
\hline Setting & Metastatic & Adjuvant & Adjuvant & Adjuvant & Adjuvant \\
\hline Neutropenia (grade 3-4) & $93.5 \%$ & $65.6 \%(P<0.001)$ & $28 \%$ & $54 \%(P<0.05)$ & $65.9 \%$ \\
\hline Fluid retention & $59.7 \%$ & $33.7 \%(P<0.001)$ & $0.3 \%$ & & \\
\hline Neurosensory disorders & $42.8 \%(P \leq 0.05)$ & $25.5 \%(P<0.001)$ & $0.8 \%$ & $1 \%$ & $36 \%$ \\
\hline Diarrhea & $50.3 \%(P \leq 0.05)$ & $35.2 \%$ & $6 \%$ & $5 \%$ & $5.4 \%$ \\
\hline Nail disorder & $44 \%(P \leq 0.05)$ & $18.5 \%$ & NA & & $28.7 \%$ \\
\hline
\end{tabular}


Table 4 Toxicity profiles of taxanes in a head to head comparison

\begin{tabular}{lllll}
\hline & Paclitaxel & Paclitaxel & Docetaxel & Docetaxel \\
weekly & 3-week cycle & cycle & weekly \\
\hline Total \% of grade 3-4 toxicities & $30 \%$ & $28 \%$ & $71 \%^{\ddagger}$ & $45 \%^{\ddagger}$ \\
Neutropenia (grade 4) & $4 \%$ & $2 \%$ & $46 \%$ & $3 \%$ \\
Febrile neutropenia (grade 3, 4) & $<0.5 \%$ & $1 \%$ & $16 \%$ & $1 \%$ \\
Edema (grades 2-4) & $3.5 \%$ & $8 \%$ & $12.5 \%$ & $10.5 \%$ \\
Nail changes (grades 2-4) & $2 \%$ & $7 \%$ & $11.5 \%$ & $10 \%$ \\
Diarrhea (grades 2-4) & $3 \%$ & $6 \%$ & $10 \%$ & $10 \%$ \\
Sensory neuropathy (grades 2-4) & $17 \%$ & $21.5 \%$ & $13 \%$ & $10.5 \%$ \\
\hline
\end{tabular}

Notes: All patients were pretreated with doxorubicin/cyclophosphamide. ${ }^{\ddagger}<0.001 .{ }^{39}$

leading to fibrosis of the lacrimal puncta and canaliculi. The frequency and toxicity grading for both docetaxel and paclitaxel change according to the dosage and scheduling.

In the E1199 Phase III clinical trial, 4,950 women with lymph node-positive or high-risk lymph node-negative breast cancer were randomized to docetaxel or paclitaxel given weekly for 12 weeks, or every 3 weeks for four cycles after receiving four cycles of AC. Docetaxel given on a 3-week cycle compared with weekly was associated with higher grade 3 and 4 neutropenia (46\% versus 3\%), febrile neutropenia (16\% versus $1 \%)$, infection $(13 \%$ versus $4 \%$ ), stomatitis ( $5 \%$ versus $2 \%$ ), myalgia and arthralgia ( $6 \%$ versus $1 \%$ ), and grades 2,3 , and 4 peripheral neuropathy $(16 \%$ versus $16 \%)$. With the exception of peripheral neuropathy, all AEs were higher in the 3-week cycle docetaxel group compared with the weekly paclitaxel group (Table 4). ${ }^{39}$

Early studies of docetaxel, confirmed by Phase III data, indicate that neutropenia is the dose limiting toxicity. The incidence of neutropenia observed in ECOG 1199 was $46 \%$ in the 3 -weekly docetaxel arm compared with only $3 \%$ when the same drug was given weekly. The incidence of febrile neutropenia was lower, at $16 \%$ and $1 \%$ for the 3 -week cycle and weekly arm, respectively. The American Society of Clinical Oncology (ASCO) Guidelines recommend prophylactic use of granulocyte colony-stimulating factors in regimens with a risk of febrile neutropenia of $20 \%$ or greater. ${ }^{40}$ In clinical practice, granulocyte colonystimulating growth factors are routinely given in 3-week cycle docetaxel regimens. Cardiac toxicity secondary to anthracycline treatment in the adjuvant treatment of breast cancer is a significant problem. ${ }^{41}$ Importantly, the Cochrane review on taxanes in breast cancer documented a reduction in cardiac toxicity that may be related to the lower cumulative doses of anthracycline therapy required when sequenced with a taxane. ${ }^{28}$ The review also reported a risk ratio of 2.32 for febrile neutropenia (95\% CI 1.1-4.4) with a reduced risk of nausea and vomiting (risk ratio $0.58 ; 95 \%$ CI $0.42-0.79){ }^{28}$

\section{Conclusion}

Docetaxel as a single agent is highly active in the treatment of metastatic breast cancer. Data support an improvement in overall survival for docetaxel in combination with capecitabine, but also an increase in toxicity. ${ }^{25}$ In HER2-positive breast cancer, the addition of pertuzumab to docetaxel and trastuzumab for first-line treatment of metastatic disease resulted in an improvement in overall survival, making this an extremely important option. ${ }^{42}$ Analyzing data from 12,000 women, the EBCTCG has reported an absolute gain of almost $3 \%$ in breast cancer mortality associated with the incorporation of taxanes into adjuvant chemotherapy regimens. Docetaxel continues to form an important backbone in early breast cancer because its toxicity profile is predictable and has been well documented. Neutropenia and febrile neutropenia are the most frequently documented AEs, but they can be managed with appropriate use of granulocyte-stimulating factors. Similarly, peripheral neuropathy can be managed with appropriate dose interruptions and delays according to recognized guidelines.

Corticosteroid premedication is required to reduce the risk of hypersensitivity reactions and fluid retention over the course of treatment. An improvement in survival was observed with weekly paclitaxel $\left(80 \mathrm{mg} / \mathrm{m}^{2}\right)$ and a 3-week docetaxel cycle $\left(100 \mathrm{mg} / \mathrm{m}^{2}\right)$ when compared with 3-week paclitaxel cycles alone $\left(75 \mathrm{mg} / \mathrm{m}^{2}\right)$. Weekly paclitaxel and 3 -week docetaxel cycles are preferable in the adjuvant setting. However, ECOG 1199 reported higher rates of grade 2 and 3 toxicity for all AEs, with the exception of peripheral neuropathy, for docetaxel compared to paclitaxel. Docetaxel is an active agent in the treatment of early and metastatic breast cancer: alone or in combination with other chemotherapeutic agents or targeted agents, it represents important standard of care treatment options. 


\section{Disclosure}

The authors report no conflicts of interest in this work.

\section{References}

1. Siegel R, Naishadham D, Jemal A. Cancer statistics, 2013. CA Cancer J Clin. 2013;63(1):11-30.

2. Kesson EM, Allardice GM, George WD, Burns WD, Morrison DS. Effects of multidisciplinary team working on breast cancer survival: retrospective, comparative, interventional cohort study of 13722 women. BMJ. 2012;344:e2718.

3. Perou CM, Sorlie T, Eisen MB, et al. Molecular portraits of human breast tumours. Nature. 2000;406:747-752.

4. Kelly CM, Bernard PS, Krishnamurthy S, et al. Agreement in risk prediction between the 21-gene recurrence score assay (Oncotype DX(®)) and the PAM50 breast cancer intrinsic Classifier ${ }^{\mathrm{TM}}$ in early-stage estrogen receptor-positive breast cancer. Oncologist. 2012;17:492-498.

5. Gelmon K, Dent R, Mackey JR, Laing K, McLeod D, Verma S. Targeting triple-negative breast cancer: optimising therapeutic outcomes. Ann Oncol. 2012;23:2223-2234.

6. Lehmann BD, Bauer JA, Chen X, et al. Identification of human triplenegative breast cancer subtypes and preclinical models for selection of targeted therapies. J Clin Invest. 2011;121:2750-2767.

7. Norton L. A Gompertzian model of human breast cancer growth. Cancer Res. 1988;48:7067-7071.

8. Bonadonna G, Brusamolino E, Valagussa P, et al. Combination chemotherapy as an adjuvant treatment in operable breast cancer. $N$ Engl J Med. 1976;294:405-410.

9. Peto R, Davies C, Godwin J, et al; Early Breast Cancer Trialists' Collaborative Group (EBCTCG). Comparisons between different polychemotherapy regimens for early breast cancer: meta-analyses of long-term outcome among 100,000 women in 123 randomised trials. Lancet. 2012;379:432-444.

10. Early Breast Cancer Trialists' Collaborative Group (EBCTCG) et al. Effects of chemotherapy and hormonal therapy for early breast cancer on recurrence and 15-year survival: an overview of the randomised trials. Lancet. 2005;365:1687-1717.

11. Paik S, Shak S, Tang G, et al. A multigene assay to predict recurrence of tamoxifen-treated, node-negative breast cancer. $N$ Engl J Med. 2004;351(27):2817-2826.

12. Parker JS, Mullins M, Cheang MCU, et al. Supervised risk predictor of breast cancer based on intrinsic subtypes. J Clin Oncol. 2009;27(8): 1160-1167.

13. Kelly CM, Hortobagyi GN. Adjuvant chemotherapy in early-stage breast cancer: what, when, and for whom? Surg Oncol Clin NAm. 2010;19(3): 649-668.

14. Guarneri V, Conte P. Metastatic breast cancer: therapeutic options according to molecular subtypes and prior adjuvant therapy. Oncologist. 2009(7)14:645-656.

15. Wani MC, Taylor HL, Wall ME, Coggon P, McPhail AT. Plant antitumor agents. VI. The isolation and structure of taxol, a novel antileukemic and antitumor agent from Taxus brevifolia. JAm Chem Soc. 1971;93(9): 2325-2327.

16. Extra JM, Rousseau F, Bruno R, Clavel M, LeBail N, Marty M. Phase I and pharmacokinetic study of Taxotere (RP 56976; NSC 628503) given as a short intravenous infusion. Cancer Res. 1993;53(5):1037-1042.

17. Guéritte-Voegelein F, Guénard D, Lavelle F, Le Goff MT, Mangatal L, Potier P. Relationships between the structure of taxol analogues and their antimitotic activity. J Med Chem. 1991;34:992-998.

18. Bissery MC, Nohynek G, Sanderink GJ, Lavelle F. Docetaxel (Taxotere): a review of preclinical and clinical experience. Part I: Preclinical experience. Anticancer Drugs. 1995;6(3):393-355, 363-368.

19. Manfredi JJ, Horwitz SB. Taxol: an antimitotic agent with a new mechanism of action. Pharmacol Ther. 1984;25(1):83-125.

20. Ringel I, Horwitz SB. Studies with RP 56976 (taxotere): a semisynthetic analogue of taxol. J Natl Cancer Inst. 1991;83:288-291.
21. Cortes JE, Pazdur R. Docetaxel. J Clin Oncol. 1995;13:2643-2655.

22. Valero V, Holmes FA, Walters RS, et al. Phase II trial of docetaxel: a new, highly effective antineoplastic agent in the management of patients with anthracycline-resistant metastatic breast cancer. J Clin Oncol. 1995;13(12):2886-2894.

23. Chan S, Friedrichs K, Noel D, et al. Prospective randomized trial of docetaxel versus doxorubicin in patients with metastatic breast cancer. J Clin Oncol. 1999;17(8):2341-2354.

24. Nabholtz J-M, Senn HJ, Bezwoda WR, et al. Prospective randomized trial of docetaxel versus mitomycin plus vinblastine in patients with metastatic breast cancer progressing despite previous anthracyclinecontaining chemotherapy. J Clin Oncol. 1999;17(5):1413-1424.

25. O'Shaughnessy J, Miles D, Vukelja S, et al. Superior survival with capecitabine plus docetaxel combination therapy in anthracyclinepretreated patients with advanced breast cancer: Phase III trial results. J Clin Oncol. 2002;20(12):2812-2823.

26. Pacilio C, Morabito A, Nuzzo F, et al; NCI-Naples Breast Cancer Group. Is epirubicin effective in first-line chemotherapy of metastatic breast cancer (MBC) after an epirubicin-containing adjuvant treatment? A single centre phase III trial. Br J Cancer. 2006;94(9):1233-1236.

27. Sparano JA, Makhson AN, Semiglazov VF, et al. Pegylated liposomal doxorubicin plus docetaxel significantly improves time to progression without additive cardiotoxicity compared with docetaxel monotherapy in patients with advanced breast cancer previously treated with neoadjuvant-adjuvant anthracycline therapy: results from a randomized phase III study. J Clin Oncol. 2009;27(27):4522-4529.

28. Ferguson T, Wilcken N, Vagg R, et al. Taxanes for adjuvant treatment of early breast cancer. Cochrane Database Syst Rev. 2007;17(4): CD004421.

29. Martin M, Pienkowski T, Mackey J, et al. Adjuvant docetaxel for nodepositive breast cancer. $N$ Engl J Med. 2005;352(22):2302-2313.

30. Francis P, Crown J, Di Leo A, et al. Adjuvant chemotherapy with sequential or concurrent anthracycline and docetaxel: Breast International Group 02-98 randomized trial. J Natl Cancer Inst. 2008;100(2): 121-133.

31. Goldstein LJ, O’Neill A, Sparano JA, et al. Concurrent doxorubicin plus docetaxel is not more effective than concurrent doxorubicin plus cyclophosphamide in operable breast cancer with 0 to 3 positive axillary nodes: North American Breast Cancer Intergroup Trial E 2197. J Clin Oncol. 2008;26:4092-4099.

32. Joensuu H, Kellokumpu-Lehtinen P-L, Bono P, et al. Adjuvant docetaxel or vinorelbine with or without trastuzumab for breast cancer. $N$ Engl J Med. 2006;354(8):809-820.

33. Coudert B, Asselain B, Campone M, et al. Extended benefit from sequential administration of docetaxel after standard fluorouracil, epirubicin, and cyclophosphamide regimen for node-positive breast cancer: the 8-year follow-up results of the UNICANCER-PACS01 trial. Oncologist. 2012;17(7):900-909.

34. Bianco ADMA, Manzione L, Boni C, et al. Taxit216 Study Group. Sequential epirubicin-cocetaxel-CMF as adjuvant therapy of early breast cancer: results of the Taxit216 multicenter phase III trial. [abstract] J Clin Oncol. 2006;24(18S):LBS520.

35. Jones SE, Savin MA, Holmes FA, et al. Phase III trial comparing doxorubicin plus cyclophosphamide with docetaxel plus cyclophosphamide as adjuvant therapy for operable breast cancer. J Clin Oncol. 2006;24(34):5381-5387.

36. Ellis P, Barrett-Lee P, Johnson L, et al. Sequential docetaxel as adjuvant chemotherapy for early breast cancer (TACT): an open-label, phase III, randomised controlled trial. Lancet. 2009;373(9676):1681-1692.

37. Martin M, Segui MA, Antón A, et al. Adjuvant docetaxel for high-risk, node-negative breast cancer. $N$ Engl J Med. 2012;363(23):2200-2210.

38. Bear HD, Anderson S, Smith RE, et al. Sequential preoperative or postoperative docetaxel added to preoperative doxorubicin plus cyclophosphamide for operable breast cancer:National Surgical Adjuvant Breast and Bowel Project Protocol B-27. J Clin Oncol. 2006;24(13):2019-2027.

39. Sparano JA, Wang M, Martino S, et al. Weekly paclitaxel in the adjuvant treatment of breast cancer. N Engl J Med. 2008;358(16):1663-1671. 
40. Smith TJ, Khatcheressian J, Lyman GH, et al. 2006 update of recommendations for the use of white blood cell growth factors: an evidence-based clinical practice guideline. J Clin Oncol. 2006;24(19): 3187-3205.

41. Carver JR, Shapiro CL, Ng A, et al. American Society of Clinical Oncology clinical evidence review on the ongoing care of adult cancer survivors: cardiac and pulmonary late effects. J Clin Oncol. 2007; 25(25):3991-4008.

42. Baselga J, Cortes J, Kim SB, et al. Pertuzumab plus trastuzumab plus docetaxel for metastatic breast cancer. $N$ Engl J Med. 2012;366(2): 109-119.
43. Fumoleau P, Chevallier B, Kerbrat P, et al. A multicentre phase II study of the efficacy and safety of docetaxel as first-line treatment of advanced breast cancer: report of the Clinical Screening Group of the EORTC. Ann Oncol. 1996;7(2):165-171.

44. Slamon D, Eiermann W, Robert N, et al. Adjuvant trastuzumab in HER2-positive breast cancer. $N$ Engl J Med. 2011;365:1273-1283.

Cancer Management and Research

\section{Publish your work in this journal}

Cancer Management and Research is an international, peer-reviewed open access journal focusing on cancer research and the optimal use of preventative and integrated treatment interventions to achieve improved outcomes, enhanced survival and quality of life for the cancer patient The journal welcomes original research, clinical \& epidemiological studies, reviews \& evaluations, guidelines, expert opinion \& commentary, case reports \& extended reports. The manuscript management system is completely online and includes a very quick and fair peerreview system, which is all easy to use. Visit http://www.dovepress.com/ testimonials.php to read real quotes from published authors.

Submit your manuscript here: http://www.dovepress.com/cancer-management-and-research-journal 